\section{Cotton Growing Problems}

By Prof. Basil G. Christidis and George J. Harrison. Pp. vii +633. (London: McGraw-Hill Publishing Co., Ltd., 1955.) 73s.

GIFTY years ago there was not much background of scientific knowledge about cotton in the field, but few crops to-day are better known, so that the biggest problem facing the cotton-grower is how to write a concise account of our garnered knowledge and to expose the gaps in it. The natural startingpoint for a grower is the seed, but the first half of this book deals with varieties, crop rotation and soil fertility; then the seed appears, to be followed up through its planting and cultivation.

This lack of balance is also evident in the use of references; there is little discrimination between major studies, minor observations and tertiary oddments.

There are large omissions, notably in the chapter on irrigation, which does not refer to the two volumes of Willcocks and Craig, nor even to my own recent book. The remarkable sixteen-year set of field experiments by D. S. Gracie is not cited until long after Part 3, on fertilization, has been concluded, and then in a line only. There is no hint that the cotton hair is built of growth-rings, that the cotton plant has a root, or that the whole crop of all varieties grown in Egypt is derived and maintained from 'individual selection'. 'The bibliography includes more than a thousand entries, in spite of omissions, but is difficult to use because it is split into eight separate groups, one for each part of the book, covering sixty-two scattered pages.

Many observations from the Greek cotton research station at Sindos by Prof. B. G. Christidis are quoted, and are evidently comprehensive. I wish that Prof. Christidis could have dealt with this, his first-hand knowledge, in more detail ; for the differences of soil and climate found under conditions in Greece can be most illuminating, and a book thus severely localized in its material would have been more generally suggestive in formulating the problems of cottongrowing.

W. Lawrence Balis

\section{The Analysis of Drugs and Chemicals}

By Dr. Norman Evers and Wilfred Smith. Pp. xii +546.. (London: Charles Griffin and Co., Ltd., 1955.) 60s. net.

THE forerunner of this book, by Evers and Elsdon, appeared more than twenty-five years ago and acquired a deserved reputation as a useful book to those engaged in the field covered by the title. Since that time, many new drugs and chemicals have come into general use, only a proportion of which have been included in the "British Pharma. copœia", or the "British Pharmaceutical Codex". The present volume deals with the official drugs and a number of the more important unofficial ones, together with those chemicals which find application in pharmacy. It is in the same form as its predecessor, but has been completely rewritten.

There is no clear-cut classification of the heterogeneous materials used in medicine, and the distinction between drugs and chemicals can only be arbitrary. Nevertheless, some sort of grouping is necessary and this has been appropriately done under the following headings: inorganic chemicals; organic chemicals; natural compounds and their derivatives ; fixed oils, fats, waxes and soaps; volatile oils; crude drugs; miscellaneous pharmaceutical materials; and galenicals and other pharmaceutical preparations. These groups are preceded by chapters on general analytical methods, and followed by one on the use of statistics in chemical analysis and by several useful appendixes.

The book is intended to supplement the "British Pharmacopœia" and the "British Pharmaceutical Codex" ; it must be used in conjunction with these volumes, since it is rarely indicated whether the substances mentioned, or the tests to be applied, are official or not. When so used, it should prove useful to the advanced student and to those engaged in the examination of named substances. It will be of only limited value to those concerned with unknown substances, for example, the toxicologist ; the "of" in the title must not be read as including "for".

\section{J. R. Nicholls}

\section{College Chemistry}

An Introductory Textbook of General Chemistry. By Prof. Linus Pauling. Second edition. (Series of Chemistry Texts.) Pp. xii +685 . (San Francisco: W. H. Freeman and Company; London: Bailey Bros. and Swinfen, Ltd., 1955.) 6 dollars; 51 s.

LOR the new edition of this book Prof. Linus Pauling has revised throughout both the text and illustrations. In the first part the facts, concepts and theories are presented more gradually and factually, and the sequence of chapters altered to provide a more systematic arrangement. Each of the six parts has an introduction describing the chapters in it and explaining why each topic is introduced in the given order. The amount of organic chemistry is increased, and at the end there are two new chapters on chemical substances related to living organisms and one on nuclear chemistry.

Chapter 3 on the electron and nuclei of atoms, in which the subjects are treated historically, is clear and easily understandable. It is followed by one on the periodic law treated on a factual basis, which is then explained on the basis of atomic structure. The descriptions of the preparation and properties of elements and compounds are related as far as possible to atomic and molecular structure. The subject of valency is particularly fully and carefully treated, and much attention is given to the geometry of molecules. The sections on physical chemistry are clear and are introduced in appropriate places. Much use is made of the historical approach throughout the book.

There is no doubt that the book has been greatly improved in the new edition. Nany teachers who desire to introduce modern aspects of theoretical chemistry into their courses will find how this can be done without sacrificing fundamental chemistry by a study of Prof. Pauling's thoughtful book.

\section{Rational Approach to Chemical Principles}

By Dr. John A. Cranston. Second edition. Pp. xii + 231. (London and Glasgow : Blackie and Son, Ltd., 1955.) 10s. $6 d$. net.

THIS small book, now in its second edition, evidently fills a need in giving a brief account of the background of physical chemistry of about intermediate degree examination standard. There may be some doubt as to whether it is really rational to introduce quantum numbers before the simple gas equation; but if students are prepared to swallow whole this preliminary summary of atomic structure, the rest is plain sailing. In the present edition, the author has included many more numerical examples in physical chemistry, which no doubt will be found useful, and the book will continue to serve a modest but useful purpose. 